Eli Lilly, GSK, Janssen, Novartis, Pfizer, and UCB; advisory board member: Eli Lilly, Janssen, Novartis, Pfizer, and UCB., X. Baraliakos Grant/research support from: AbbVie, BMS, Celgene, Chugai, Merck, Novartis, Pfizer, UCB, and Werfen, Consultant for: AbbVie, BMS, Celgene, Chugai, Merck, Novartis, Pfizer, UCB, and Werfen, Speakers bureau: AbbVie, BMS, Celgene, Chugai, Merck, Novartis, Pfizer, UCB, and Werfen, H. Marzo-Ortega Grant/research support from: Janssen and Pfizer, Consultant for: AbbVie, Celgene, Janssen, Novartis and UCB, Speakers bureau: Abbvie, Celgene, Janssen and UCB, J. Sieper Grant/research support from: for AbbVie, Boehringer Ingelheim, Janssen, Novartis, Merck, Lilly, Pfizer, and UCB, Consultant for: for AbbVie, Boehringer Ingelheim, Janssen, Novartis, Merck, Lilly, Pfizer, and UCB, M. Andersson Employee of: Novartis, B. Porter Shareholder of: Novartis, Employee of: Novartis, T. Fox Shareholder of: Novartis, Employee of: Novartis DOI: 10.1136/annrheumdis-2017-eular.4894

\section{THU0360 IMPROVEMENTS IN SLEEP PROBLEMS AND PAIN IN PATIENTS WITH ACTIVE ANKYLOSING SPONDYLITIS TREATED WITH INTRAVENOUS GOLIMUMAB: 28-WEEK RESULTS OF THE PHASE III GO-ALIVE TRIAL}

A. Deodhar ${ }^{1}$, J.D. Reveille ${ }^{2}$, E.K. Chan ${ }^{3}$, S. Peterson ${ }^{4}$, N. Li ${ }^{4}$, E. Hsia ${ }^{4,5}$ L. Kim ${ }^{4}$, K.H. Lo ${ }^{4}$, D.D. Harrison ${ }^{4}$, C. Han ${ }^{6} .{ }^{1}$ Oregon Health \& Science University, Portland; ${ }^{2}$ University of Texas Health Sciences Center, Houston;

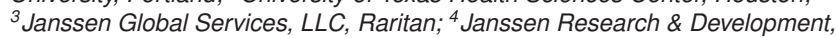
LLC, Spring House; ${ }^{5}$ University of Pennsylvania School of Medicine, Philadelphia; ${ }^{6}$ Janssen Global Services, LLC, Malvern, United States

Objectives: To investigate the effect of intravenously administered (IV) Golimumab (2 mg/kg), an anti-TNF $\alpha$ monoclonal antibody, on sleep problems, total back pain, and night back pain in adult patients (pts) with active Ankylosing Spondylitis (AS). Methods: GO-ALIVE is a Phase 3 , multicenter, randomized, double-blind, placebo-controlled trial. Pts (aged $\geq 18$ years) had a diagnosis of definite AS (per modified New York criteria) and BASDAI $\geq 4$, total back pain visual analogue scale $(\mathrm{VAS}) \geq 4$, and CRP $\geq 0.3 \mathrm{mg} / \mathrm{dL}$. At baseline, 208 pts were randomized to IV golimumab $2 \mathrm{mg} / \mathrm{kg}(\mathrm{N}=105)$ at Wks 0,4 , and every 8 wks or placebo $(\mathrm{N}=103)$ at Wks 0,4 , and 12 , with crossover to IV golimumab at Wk 16 and through Wk 52. Sleep problems were assessed using the Medical Outcomes Study Sleep Scale (MOS-SS, range 0-100), a generic instrument designed to assess six dimensions of sleep, including 1) Sleep disturbance, 2) Somnolence, 3) Sleep adequacy, 4) Snoring, 5) Awaken short of breath or headache, and 6) Quantity of sleep/optimal sleep during the past 4 wks. The six dimensions are also used to generate the composite Sleep Problems Index. An increase in score from baseline represents improvement. Total back pain and night back pain over the past wk were assessed using VAS $(0-10 \mathrm{~cm} ; 0=$ no pain, 10=most severe pain). Wk 28 results are presented here. Unadjusted p-values of least square mean differences (LSMD) between treatment groups were based on analysis of covariance (ANCOVA) controlling for prior anti-TNF therapy.

Results: Mean changes in MOS-SS Sleep Index and 6 subscales are presented in Table 1. Improvement $(p<0.05)$ in the MOS-SS sleep index and 4 subscales at Wk 8 was observed in golimumab compared to placebo, and in the sleep index and 4 subscales at Wk 16. Improvements from baseline to Wks 8 and 16 in pts' assessment of total back pain $(\mathrm{cm})$ were greater $(p<0.001)$ in golimumab than placebo $(-2.70$ vs -0.86 and -3.15 vs -1.15 , respectively), and after placebo crossed over to golimumab, the differences diminished at Wk 28 (-3.14 vs -3.34 , respectively). Improvements at Wks 8 and 16 from baseline in pts' assessment of night back pain $(\mathrm{cm})$ were also greater $(p<0.001)$ in golimumab than placebo ( -3.03 vs -0.87 and -3.44 vs -0.85 , respectively), and differences diminished at Wk 28 (-3.47 vs -3.42 , respectively). Changes from baseline in all subscales of MOS-SS were correlated (Spearman correlations ranging between -0.10 and -0.45 ) with total back pain (TBP) and night back pain (NBP) at Wks 8, 16, and 28 ( $p$ values $<0.05$, with the exception of Snoring and both TBP and NBP at Wk 16. Change in NBP was associated with change in Sleep Problem Index at all 3 time points $(p=0.002, p=0.001$, and $p=0.031$, respectively). In the general linear model, most of the association between change in TBP and change in Sleep Problem Index was explained by the association between change in NBP and change in Sleep Problem Index.

Table 1. Summary of mean (standard deviation) changes in MOS-SS and its subscales.

\begin{tabular}{|c|c|c|c|c|c|c|}
\hline & GLM & PBO & GLM & PBO & GLM & PBO* \\
\hline MOS-SS & $\mathrm{N}=104$ & $\mathrm{~N}=102$ & $N=104$ & $\mathrm{~N}=102$ & $\mathrm{~N}=104$ & $\mathrm{~N}=102$ \\
\hline & \multicolumn{2}{|c|}{ Week 8} & \multicolumn{2}{|c|}{ Week 16} & \multicolumn{2}{|c|}{ Week 28} \\
\hline \multicolumn{7}{|l|}{$\begin{array}{l}\text { Mean (SO) change from } \\
\text { baseline in: }\end{array}$} \\
\hline Sleep problems index: & $\begin{array}{c}5.10(7.86) \\
p<0.001\end{array}$ & $1.72(7.36)$ & $\begin{array}{l}6.63(7.18) \\
p<0.001\end{array}$ & $2.49(8.16)$ & $6.58(8.05)$ & $5.88(8.29)$ \\
\hline Sleep disturbance: & $\begin{array}{c}4.44(8.81) \\
p=0.001\end{array}$ & $1.32(7.09)$ & $\begin{array}{c}6.08(7.76) \\
p<0.001\end{array}$ & $2.37(7.88)$ & $6.32(8.42)$ & $5.07(8.17)$ \\
\hline Somnolence: & $\begin{array}{c}3.37(7.34) \\
p=0.016\end{array}$ & $1.21(8.58)$ & $\begin{array}{l}5.27(7.05) \\
p<0.001\end{array}$ & $1.47(8.18)$ & $4.82(7.87)$ & $4.54(7.81)$ \\
\hline Sleep adequacy: & $\begin{array}{c}3.12(8.24) \\
p=0.037\end{array}$ & $1.80(8.59)$ & $\begin{array}{c}.14(8.36) \\
p=0.012\end{array}$ & $2.09(8.93)$ & $3.73(7.88)$ & $5.75(10.15)$ \\
\hline Snoring: & $\begin{array}{c}1.97(7.71) \\
p=0.30\end{array}$ & $0.82(6.58)$ & $\begin{array}{c}1.24(7.72) \\
p=0.98\end{array}$ & $1.04(6.24)$ & $1.90(7.39)$ & $0.89(7.28)$ \\
\hline $\begin{array}{l}\text { Awaken short of breath } \\
\text { or headache: }\end{array}$ & $\begin{array}{c}4.64(12.44) \\
p=0.043\end{array}$ & $1.15(10.02)$ & $\begin{array}{c}4.08(12.26) \\
p=0.20\end{array}$ & $1.50(11.20)$ & $4.19(12.50)$ & $3.00(11.21)$ \\
\hline $\begin{array}{l}\text { Quantity of } \\
\text { sleep/optimal sleep: }\end{array}$ & $\begin{array}{c}0.13(0.57) \\
p=0.43\end{array}$ & $0.10(0.52)$ & $\begin{array}{c}0.13(0.59) \\
p=0.019\end{array}$ & $0.01(0.57)$ & $0.16(0.56)$ & $0.19(0.56)$ \\
\hline
\end{tabular}

Conclusions: Adult pts with active AS treated with IV golimumab showed improvements in sleep problems, total back pain, and night back pain. Night back pain improvement was associated with improvement in sleep problems.

Disclosure of Interest: A. Deodhar Grant/research support from: Janssen, Amgen, Abbvie, GSK, Eli Lilly, Novartis, Pfizer, UCB, Consultant for: Janssen, Eli Lilly, Novartis, Pfizer, UCB, J. Reveille Grant/research support from: Janssen Scientific Affairs, LLC., E. Chan Employee of: Janssen Global Services, LLC, S. Peterson Employee of: Janssen Research \& Development, LLC, N. Li Employee of: Janssen Research \& Development, LLC, E. Hsia Employee of: Janssen Research \& Development, LLC, L. Kim Employee of: Janssen Research \& Development, LLC, K. H. Lo Employee of: Janssen Research \& Development, LLC, D. Harrison Employee of: Janssen Research \& Development, LLC, C. Han Employee of: Janssen Global Services, LLC DOI: 10.1136/annrheumdis-2017-eular.5325

\section{THU0361 PRESCRIPTION PATTERNS OF BIOLOGICAL DISEASE MODIFYING DRUGS AND BIOSIMILARS IN ANKYLOSING SPONDYLITIS - A COLLABORATION BETWEEN BIOLOGICAL REGISTERS IN THE FIVE NORDIC COUNTRIES}

B. Glintborg ${ }^{1}$, K. Chatzidionysiou ${ }^{2}$, J. Askling ${ }^{2}$, K. Aaltonen ${ }^{3}$, E. Kristianslund ${ }^{4}$ B. Gudbjornsson ${ }^{5}$, D. Nordström ${ }^{3}$, M.L. Hetland ${ }^{1}$, L. Dreyer ${ }^{1}$, L.E. Kristensen ${ }^{1}$, T.S. Jørgensen ${ }^{1}$, K. Eklund ${ }^{3}$, G. Grondal ${ }^{5}$, S. Ernestam ${ }^{2}$, J. Joensuu ${ }^{3}$, T. Kvien ${ }^{4}$, E. Lie ${ }^{4}$, K. Fagerli ${ }^{4}$, A.J. Geirsson ${ }^{5}$, H. Jonsson ${ }^{5}$, L. Jacobsson ${ }^{2}$. ${ }^{1}$ On behalf of the DANBIO registry, Copenhagen, Denmark; ${ }^{2}$ On behalf of the SRQ/ARTIS registry, Stockholm, Sweden; ${ }^{3}$ On behalf of the ROB-FIN registry, Helsinki, Finland; ${ }^{4}$ On behalf of the NOR-DMARD registry, Oslo, Norway; ${ }^{5}$ On behalf of the ICEBIO registry, Reykjavik, Iceland

Background: Large-scale real life observational cohorts are needed to study effectiveness and early signals of rare safety issues of new biological disease modifying drugs (bDMARDs) and biosimilars (bsDMARDs) in ankylosing spondylitis (AS). Combining data from biological registries would facilitate this. The Nordic countries have several similarities that would justify such aggregated analyses including similar health care systems with universal access to population based health care, availability of b/bsDMARDs through a tax-paid system and the registration of use and effectiveness of bDMARDs in inflammatory diseases in a prospective manner in drug registries.

Objectives: To explore the prescription patterns of old (TNF-inhibitors) and newer bDMARDs (secukinumab, ustekinumab) including bsDMARDs (SB4, CT-P13) over time in AS in the Nordic countries in order to illustrate the potential of a common Nordic collaboration.

Methods: Data regarding the numbers of AS patients (pts) (ICD10 code M45) who initiated bDMARD treatment (irrespective of treatment course number) during the period 2011-2016 were collected from the Nordic rheumatologic biological registries SRQ (Sweden), NOR-DMARD (6 Norwegian treatment centres), DANBIO (Denmark), ROB-FIN (Finland, 2011-2015) and ICEBIO (Iceland).

Results: In total, 6,610 bDMARD treatment initiations were identified (Sweden 3654 , Norway 1078, Denmark 782, Finland 789, Iceland 307).

The prescription patterns of bDMARDs changed substantially over time. In 2016, the number of pts initiating a bsDMARDs exceeded those starting an originator bDMARD (figure). Few patients were treated with ustekinumab (Denmark $<10$ pts, Finland $<10$, Sweden 26) and secukinumab (Denmark $<10$ pts, Sweden 57).

Figure. The 5 Nordic countries, total number of AS patients initiating bDMARD per year

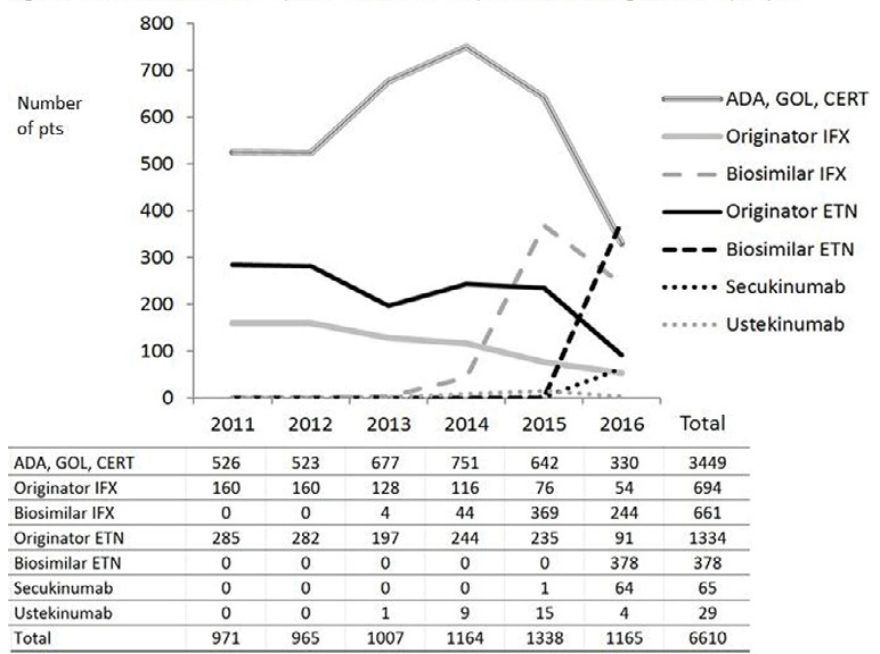

ADA: Adalimumab, GOL: Golimumab, CERT: Certolizumab Pegol, IFX: Infliximab, ETN: Etanercept

Conclusions: The use of bsDMARDs in AS is rapidly increasing. The use of drugs with new modes of action is still low, which illustrates the need for collaboration across countries to provide real life data with sufficient power for new innovative therapies in the future. The Nordic rheumatologic registries represent a unique 
opportunity to study effectiveness and safety of bDMARDs, including bsDMARDs in AS.

Acknowledgements: Partly funded by a grant from NordForsk

Disclosure of Interest: B. Glintborg Grant/research support from: abbvie, K. Chatzidionysiou: None declared, J. Askling Grant/research support from: AbbVie, Eli Lilly, Janssen, Merck, Pfizer, Roche, UCB, Samsung, K. Aaltonen Speakers bureau: AbbVie, BMS, Janssen, MSD, Pfizer, Roche, UCB, E. Kristianslund: None declared, B. Gudbjornsson Grant/research support from: Actavis, Celgene, MSD, Pfizer, D. Nordström Speakers bureau: AbbVie, BMS, Lilly, MSD, Novartis, Pfizer, Roche, UCB, M. Hetland Grant/research support from: Orion, BMS, AbbVie, Biogen, Pfizer, MSD, L. Dreyer Speakers bureau: MSD, UCB, Janssen Pharmaceuticals, L. E. Kristensen Speakers bureau: Pfizer, AbbVie, Biogen, Amgen, UCB, Celegene, BMS, MSD, Novartis, Eli Lilly, Janssen pharmaceuticals, T. Jørgensen Speakers bureau: AbbVie, Roche, Novartis, UCB, Biogen, K. Eklund: None declared, G. Grondal: None declared, S. Ernestam: None declared, J. Joensuu Grant/research support from: Pfizer, T. Kvien Speakers bureau: AbbVie, Biogen, BMS, Boehringer Ingelheim, Celltrion, Eli Lilly, Epirus, Janssen, MerckSerono, MSD, Mundipharma, Novartis, Oktal, Orion Pharma, Hospira/Pfizer, Roche, Sandoz, UCB, E. Lie Speakers bureau: AbbVie, Celgene, Hospira, Pfizer, K. Fagerli: None declared, A. J. Geirsson: None declared, H. Jonsson: None declared, L. Jacobsson Consultant for: Abbvie, Celegen, MSD, Novartis, UCB DOI: 10.1136/annrheumdis-2017-eular.1891

\section{THU0362 EFFECT OF BIOTECHNOLOGICAL DRUGS ON EXTRA-ARTICULAR MANIFESTATIONS OF ANKYLOSING SPONDYLITIS: SYSTEMATIC REVIEW}

A.L.R. Pinto ${ }^{1}$, C.V. Pessoa ${ }^{1,2}$, L.S. Inês ${ }^{1,3} \cdot{ }^{1}$ Faculty of Health Sciences, University of Beira Interior, Covilhã; ${ }^{2}$ Rheumatology, Local Health Unit of Guarda, Guarda; ${ }^{3}$ Rheumatology, Coimbra Hospital and Universitary Centre, Coimbra, Portugal

Background: Treatment with biotechnological agents (infliximab, etanercept, adalimumab, golimumab and certolizumab pegol) in ankylosing spondylitis (AS) is effective. However, evidence regarding the potential efficacy of these anti-TNF drugs in the extra-articular manifestations of ankylosing spondylitis, namely in uveitis (UV), inflammatory bowel disease (IBD) and dactylitis is scarce.

Objectives: To analyze evidence on efficacy of anti-TNF drugs approved for AS treatment in UV, IBD and dactylitis associated with AS.

Methods: A systematic literature review was performed using the PubMed and Cochrane Library databases. Randomized controlled trials (RCT), metaanalyzes and observational studies (OS) reporting efficacy of anti-TNF agents in extra-articular manifestations of AS were included.

Results: Fifty studies were included (seventeen RCTs, six meta-analyses and twenty seven observational studies). From the RCT we extracted the results presented in Table 1 for uveitis and in Table 2 for IBD. None reported results for dactylitis. Of the meta-analyzes included, only one presents results. These one shows that the incidence of uveitis is lower in patients taking etanercept than placebo (incidence of 8.6 and 19.3 per 100 patients per year, respectively; $p$ value $=0.03$ ). In OS comparing different drugs, in one the risk of developing uveitis was 1.9 times higher in patients under etanercept compared to those under adalimumab ( $p$ value $=0.0223$ ) and a risk similar to those under infliximab and those under adalimumab. In another we have a percentage of patients with uveitis, during the course of the study, under etanercept of $8.0 \%$ and under infliximab of $4.0 \%$. In the OS, the percentage of patients with UV events with infliximab was in a range of $0.0 \%>3.1 \%$ with a follow-up interval between 2 years and 5 years; with etanercept was $0.9 \%>29.6 \%$ and a follow-up time interval between 12 weeks to 7 years; with adalimumab there is only one study with duration of 2 years reporting $3.9 \%$ UV events. Regarding IBD reported in OS, there was 3.7\% $>7.7 \%$ patients with events under treatment with etanercept over a follow-up time of 3.2-7 years; with adalimumab only a 2 -year study reported IBD in $0.6 \%$ of cases. We did not find results regarding for other extra-articular manifestations or anti-TNF drugs.

Table 1. Percentage of patients with events of uveitis on Randomized Controlled Trials

\begin{tabular}{lcc}
\hline Uveitis & \multicolumn{2}{c}{ Randomized Controlled Trials } \\
\cline { 2 - 3 } & \% patients with events under therapy \% patients with events under placebo \\
\hline Infliximab & 2,9 & 8,6 \\
Etanercept & 1,1 & 3,5 \\
Adalimumab & No results & No results \\
Golimumab & No results & No results \\
Certolizumab pegol & 0,9 & 2,8 \\
\hline
\end{tabular}

Table 2. Percentage of patients with events of inflammatory bowel disease on Randomized Controlled Trials

\begin{tabular}{lcc}
\hline Inflammatory Bowel & \multicolumn{2}{c}{ Randomized Controlled Trials } \\
\cline { 2 - 4 } Disease & \% patients with events under therapy \% patients with events under placebo \\
\hline Infliximab & No results & No results \\
Etanercept & 1,1 & 0,7 \\
Adalimumab & 1,0 & 0,0 \\
Golimumab & No results & No results \\
Certolizumab pegol & 0,0 & 0,9
\end{tabular}

Conclusions: Efficacy of anti-TNF drugs on extra-articular manifestations of AS

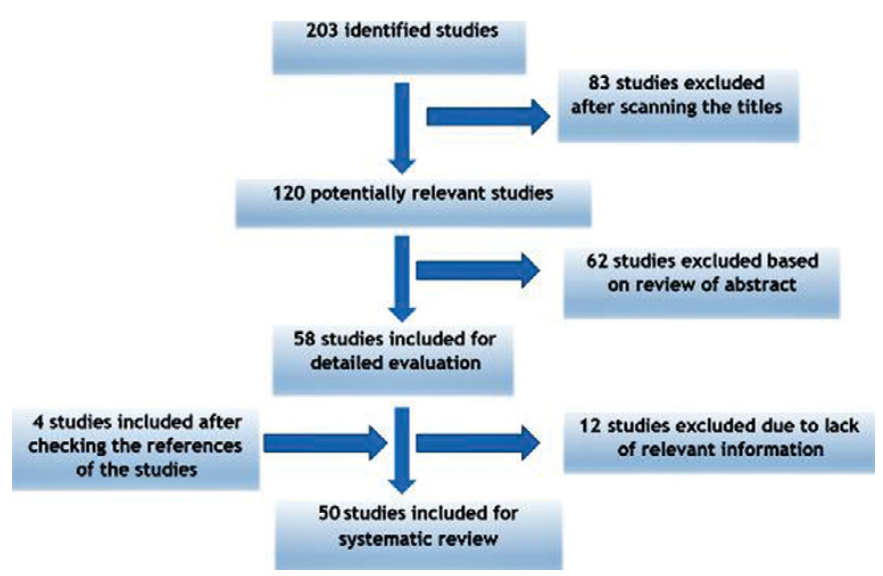

is under-reported in RCTs. Available data suggests possible efficacy of infliximab, adalimumab and certolizumab in UV, and of certolizumab in IBD. No evidence is available about anti-TNF efficacy in AS-associated dactylitis. Future studies with anti-TNF drugs should better report on extra-articular manifestations in AS.

Disclosure of Interest: None declared

DOI: 10.1136/annrheumdis-2017-eular.5138

\section{THU0363 IMPACT OF ADALIMUMAB ON CLINICAL OUTCOMES, HEALTHCARE RESOURCE UTILIZATION AND SICK LEAVES IN ANKYLOSING SPONDYLITIS PATIENTS IN CENTRAL AND EASTERN EUROPE}

D. Opris-Belinski ${ }^{1}$, S. Erdes ${ }^{2}$, S. Grazio ${ }^{3}$, L. Šenolt ${ }^{4}$, M. Hojnik ${ }^{5}$, O. Nagy ${ }^{6}$, L. losub ${ }^{7}$, S. Szántó ${ }^{8} .{ }^{1}$ Rheumatology, Sf. Maria Clinical Hospital, Carol Davila University of Medicine, Bucharest, Romania; ${ }^{2}$ V. A. Nasonova Research Institute of Rheumatology, Moscow, Russian Federation; ${ }^{3}$ Univ. Dpt. of Rheumatology, Clinical Hospital Centre Sisters of Mercy, Croatia, Zagreb, Croatia; ${ }^{4}$ Dpt. of Rheumatology, 1st Faculty of Medicine, Charles Univ, Institute of Rheumatology, Prague, Czech Republic: ${ }^{5}$ AbbVie, Global Medical Affairs, Ljubliana, Slovenia; ${ }^{6}$ AbbVie, Global Medical Affairs, Budapest, Hungary; ${ }^{7}$ AbbVie, Global Medical Affairs, Bucharest, Romania; ${ }^{8}$ Rheumatology, Faculty of Medicine, Univ. of Debrecen, Debrecen, Hungary

Background: Ankylosing spondylitis (AS) represents a considerable socioeconomic burden due to early disease onset, development of functional disability and life-time costs. The impact of originator adalimumab on the extent of outpatient attendance, hospitalizations and sick leave in relation to clinical outcomes is not known in Central and Eastern Europe (CEE).

Objectives: To evaluate disease activity, physical function, selected health care resource utilization and sick leaves in patients treated with adalimumab in clinical practice in CEE countries.

Methods: This was a 52-week multi-center post-marketing observational study conducted in 5 countries in CEE. Eligible AS patients were prescribed originator adalimumab according to the local practice; 5 study visits $(\mathrm{V})$ were performed approx. 3 months apart. Disease activity was measured by Bath Ankylosing Spondylitis Disease Activity Index (BASDAI) and Ankylosing Spondylitis Disease Activity Index (ASDAS ${ }_{\text {CRP) }}$, treatment response as BASDAI50 and $\triangle A S D A S \geq-2$ (at study end), physical function by Bath Ankylosing Spondylitis Functional Index (BASFI). Data on AS related healthcare resource utilization and sick leave during the study was recorded prospectively through a systematic interview with the patient at each study visit. For pre-and post-treatment comparison, the same sort of data were recorded retrospectively at baseline visit for the 3-month period preceding adalimumab therapy, verified against chart review, then multiplied by 4 to match the prospective follow-up duration. Descriptive statistics were used; last observation carried forward data are presented herein.

Results: 452 patients were enrolled, 360 completed the study. Mean age was 42.9 ( \pm 12.1$)$ yrs; $68.7 \%$ were male and $62.7 \%$ were employed at baseline. Average disease duration was $7.7( \pm 8.7)$ yrs. Mean BASDAI and ASDAS decreased from $6.3( \pm 2.1)$ and $4.0( \pm 1.1)$ at baseline to $2.3( \pm 2.0)$ and $1.9( \pm 1.1)$ at study end, respectively; mean BASFI from $6.2( \pm 2.3)$ to $2.6( \pm 2.3)$. BASDAI and ASDAS based treatment response was seen at study end in $72.3 \%$ and $58.9 \%$ of patients, respectively. The mean number of hospital admissions and inpatient days decreased from $2.8( \pm 3.9)$ to $0.9( \pm 2.8)$ and from $23.0( \pm 40.8)$ to $3.9( \pm 17.7)$, respectively (pre- and post-treatment). The mean number of sick leaves and sick leave days decreased from $3.2( \pm 8.8)$ to $1.1( \pm 5.6)$ and from $32.2( \pm 69.2)$ to $5.1( \pm 24.5)$, respectively (employed patients only, $n=282$ ). The reduction of hospital admissions/days, sick leaves and sick leave days were higher in treatment responders compared to non-responders. No new safety signal was detected. Conclusions: Treatment with adalimumab in routine clinical practice in $5 \mathrm{CEE}$ countries resulted in clinically meaningful improvements in disease activity and physical function as well as reduced healthcare resource utilization and sick leaves.

Acknowledgements: The design, study conduct, and financial support for the 